\title{
Dark Triad, Sociosexual Orientation and Religious Affiliation: An Association and Moderation Study
}

\author{
Bobby Haddad ${ }^{1}$, Mia Ångman ${ }^{1}$, Trevor Archer ${ }^{2,3}$ and Danilo Garcia ${ }^{2-6^{*}}$ \\ ${ }^{1}$ Department of Psychology, Linneaus University, Växjö, Sweden \\ ${ }^{2}$ Department of Psychology, University of Gothenburg, Gothenburg, Sweden \\ ${ }^{3}$ Network for Empowerment and Well-Being, Sweden \\ ${ }^{4}$ Blekinge Center for Competence, Blekinge County Council, Karlskrona, Sweden \\ 5Institute of Neuroscience and Physiology, University of Gothenburg, Gothenburg, Sweden \\ ${ }^{6}$ Department of Psychology, Lund University, Lund, Sweden
}

*Corresponding author: Danilo Garcia, Network for Empowerment and Well-Being, Axel W Anderssonsväg 8 A, SE 37162 Lyckeby, Sweden, Tel: +46 31-786 0000; Email: danilo.garcia@icloud.com

Received date: May 02, 2016; Accepted date: May 21, 2016; Published date: May 28, 2016

Copyright: ( 2016 Haddad B, et al. This is an open-access article distributed under the terms of the Creative Commons Attribution License, which permits unrestricted use, distribution and reproduction in any medium, provided the original author and source are credited.

\begin{abstract}
Objective: We examined the relationships between individuals' malevolent tendencies (i.e., the Dark Triad: Machiavellianism, narcissism, and psychopathy), sociosexual orientation (i.e., behavior, attitude, and desire to participate in uncommited sex) and religious affiliation.

Method: The participants consisted of US-residents $(N=309)$ who responded to an online survey through Amazon's Mechanical Turk (MTurk). A correlation analysis was used to investigate the association between variables and multiple regression analyses were used to investigate if religious affiliation moderated the effect of the Dark Triad composite (i.e., the sum of the three dark traits) on global sociosexual orientation.

Results: The Dark Triad traits had a positive relationship with each of the dimensions of sociosexual orientation, but only psychopathy was significantly negatively related to religious affiliation. Religious affiliation, in turn, was negatively related to sociosexual orientation and its' dimensions. Religious affiliation, however, did not moderate the effect of Dark Triad on sociosexual orientation.
\end{abstract}

Conclusion: Our findings confirm the impact of religiousness/spirituality upon aspects of malevolent character traits, that is, deviant sexual orientation.

Keywords: Dark triad; Machiavellianism; Moderation; Narcissism; Psychopathy; Religious affiliation; Sociosexual orientation

\section{Introduction}

"Since love and fear can hardly exist together, if we must choose between them, it is far safer to be feared than loved".

Individuals' dark tendencies include malevolent character traits such as Machiavellianism, narcissism, and psychopathy [1]. Only narcissism and psychopathy have clinical descriptions [2] Machiavellianism as a concept was derived from Niccolò Machiavelli's (advisor to the Medicis) tactics and philosophy [3]. Machiavellianism incorporates the propensity for lies, treachery, manipulation, and forceful persuasion that a leader may apply to achieve political and social power [4]. Cynicism, lack of principles, and the conviction that manipulation gives success are common among individuals who are high in Machiavellianism. These individuals also exhibit emotional frigidity, immoral strategic thinking, long-sightedness and motivations dictated by money and power. These individuals are not averse to betrayal, exploitation [3,5], and sexual promiscuity and enmity [5]. In the work environment, they display cunning and ruthlessness to obtain political goals [4] and financial success [6]. Individuals presenting
Machiavellian attributes may persuade and influence others for their own personal benefit, often abusing their power as leaders through dominant behavior. In the context of the general population, subclinical narcissicism includes grandiosity and convictions of once own right and supremacy. Individuals high in narcissism are convinced they are unique and exhibit a high degree of conceit vanity, arrogance, and demand admiration from others. They may demonstrate hostility, insensitivity, disdainfulness, and lack of empathy. They often display a self-reinforcing notion of positive outcomes due to their talents, whereas negative outcomes are explained by 'fate' or the deficiencies of others [7]. In addition, high levels of narcissism correlate negatively with integrity, dependability, and trust [8]. The subclinical notion of psychopathy is associated with high levels of impulsiveness, sensationseeking and with both manipulative and antisocial behavior [1,9]. Psychopathy is also negatively correlated with conscientiousness [1] and friendliness [2], while positively correlated to extraversion and openness [1], as well as verbal and physical aggressiveness [10]. In addition, psychopathy is negatively correlated with serious romantic relationships $[10,11]$. In sum, individuals who express these malevolent character traits also tend to have opportunistic short-term relationships with a pragmantic and sarcastic attitude towards love $[10,12]$. 
In contrast, individuals with restrictive sociosexual orientations prefer love, relationship engagement and emotional closeness rather than temporary sex [13]. Sociosexuality describes individuals' propensities for opportunistic, temporary sexual relations [14] in different dimensions: (i) behavior, (ii) attitude, and (iii) desire [15]. The behavior dimension (i) reflects individuals previous sexual experience, relationships, and infidelity. The attitude dimension (ii) reflects aspects of behavior and desire influenced by moral feelings, reflections and self-presentation based on values, habits and social effects. The desire dimension (iii) presents the notion of a dispositional motivation that refers to effort given to temporary and long-term sexual relationships.

In this context, there appears to be a positive relationship between religion and spirituality and several markers of physical health [16]. Religion shows also positive links to personal attributes, such as friendliness, which is associated negatively with the dark triad components [2]. Religion and spiritual well-being are linked negatively to psychiatric disorders such as anxiety, depression, and narcomania [17]. Some of these, in turn, positively associated to Machiavellianism, narcissism, and psychopathy [18]. In summary, the Dark Triad appears to be associated with sociosexual orientation while being affiliated to a religion shows negative associations to both the former and the latter.

The purpose of the present study was twofold: (i) to examine associations between the Dark Triad, sociosexual orientation and religious affiliation and (ii) to ascertain whether or not being affiliated to a religion moderated the effects of Dark Triad traits upon sociosexual orientation.

\section{Method}

\section{Participants and procedure}

A total of 309 individuals participated in the study of whom 104 were female $(M=29.02$ years, $S D=8.1$, Range 18-57 $)$ and 205 were male $(\mathrm{M}=31.96$ years, $\mathrm{SD}=10.2$, Range 18-71). MTurk allows data collectors to recruit participants online for completing different tasks in exchange for wages. This method of data collection online has become more common during recent years and it is an empirically tested tool for conducting research in the social sciences [19]. Participants were recruited by the criteria of being a US-resident and the ability to read and write fluently in English. Participants were paid a wage of 0.50 cents (US-dollars) for completing the task and informed that the study was confidential and voluntary. Participants responded to questionnaires measuring the Dark Triad, sociosexual orientation and religious affiliation, as well as demographic questions on marital status, employment, gender, age, and two control questions, e.g. "In this question please answer Neither agree or disagree". Nine participants responded incorrectly to the control question and were therefore eliminated from the final sample (i.e., 2.91\%).

\section{Measures}

The Dark Triad Dirty Dozen [10]. This instrument consists of 12 statements $(1=$ strongly disagree, $7=$ strongly agree $)$ with four statements for each dark trait: Machiavellianism ("I tend to manipulate others to get my way"; $\alpha=0.82$ ), narcissism ("I tend to want others to admire me"; $\alpha=0.77$ ), and psychopathy ("I tend to be unconcerned with the morality of my actions"; $(\alpha=0.77)$. The three traits combined (i.e., the Dark Triad composite) had good reliability ( $\alpha=0.84$.). This instrument has showed good internal consistency and test-retest reliability in earlier studies $[10,20,21]$.

Sociosexual Orientation Inventory Revised [15]. This test consist of nine statements $(1=$ strongly disagree, $9=$ strongly agree) that measure the three soxiosexual dimensions: behavior ("With how many different partners have you had sexual intercourse on one and only one occasion?"; $\alpha=0.79$ ), attitude ("Sex without love is OK"; $\alpha=0.86$ ), and lust ("In everyday life, how often do you have spontaneous fantasies about having sex with someone you have just met?"; $\alpha=0.87$ ). The global sociosexual orientation (i.e., the sum of all three dimensions) showed here good reliability: $\alpha=0.87$.

Religious affiliation: Participants were asked to indicate their religious affiliation in any of the following alternatives: $0=$ none $(\mathrm{n}=$ 182), 1 = Roman Catholic $(\mathrm{n}=52), 2$ = Evangelic Christian $(\mathrm{n}=60), 3$ $=$ Jewish $(\mathrm{n}=6), 4=$ Muslim $(\mathrm{n}=0), 5=$ Hindu $(\mathrm{n}=1), 6=$ Buddist $(\mathrm{n}$ $=8), 7=$ other $(\mathrm{n}=0)$. For the analyses, we divided the whole sample in individuals with no religious affiliation $(\mathrm{n}=182)$ and individuals with any religious affiliation $(\mathrm{n}=127)$.

\section{Statistical analysis}

A Pearson's correlation analysis was conducted to investigate associations between the Dark Triad traits, sociosexual orientation, and religious affiliation. We conducted a three-step hierarchical regression analysis to investigate whether or not religious affiliation had an effect on the relationship between the Dark Triad composite and global sociosexual orientation. The predictor variable in the analysis was the Dark Triad composite, the moderation variable was religious affiliation, and the outcome variable was the global sociosexual orientation (see Figure 1). Assumptions necessary for linear regression analysis were met [22], as well as the test of independence of data (Durbin-Watson's test $=1,903$ ). 
Citation: Haddad B, Angman M, Archer T, Garcia D (2016) Dark Triad, Sociosexual Orientation and Religious Affiliation: An Association and

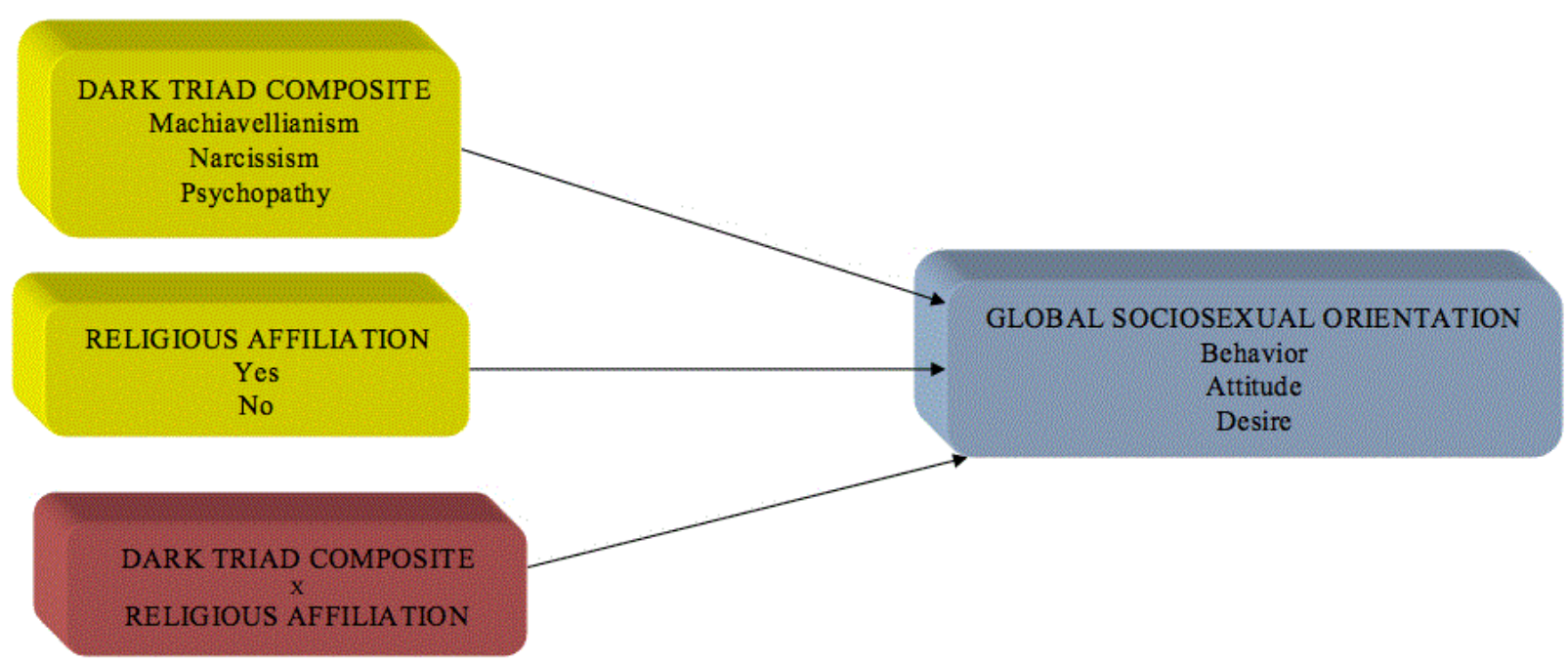

Figure 1: Moderation model of the relationship between Dark Triad (predictor), religious affiliation (moderator), and sociosexual orientation (outcome).

\section{Results and Discussion}

There were significant positive correlations between the Dark Triad traits and both global sociosexual orientation and its dimensions (i.e., behavior, attitude and lust). There were also significant negative correlations between religious affiliation and psychopathy and between religious affiliation and global sociosexual and its dimensions (i.e., behavior, attitude, lust. See Table 1 for the details.

The results of correlational analysis confirmed associations between the Dark Triad, sociosexual orientation and religion thereby reinforcing the notion that the Dark Triad attributes are linked to a less restrictive sociosexual orientation $[5,11,12,23,24]$. Religious affiliation showed a negative relationship with psychopathy, sociosexual orientation, behavior and attitude which is hardly surprising since these components tend to influence the norms and values of society that regulate sexuality [25]. Nevertheless, it is likely that individual lust for sexual intercourse is regulated biologically [26]. The negative association between religion and psychopathy is not surprising, seeing that individuals high in psychopathy are antisocial, have low levels of attachment, and lack both transcendence and empathy. In other words, all of these characteristics are high among spiritual individuals, but absent among individuals high in psychopathy $[2,16,17]$.

\begin{tabular}{|c|c|c|c|c|c|c|c|c|c|c|c|c|}
\hline & M & SD & $\alpha$ & 1 & 2 & 3 & 4 & 5 & 6 & 7 & 8 & 9 \\
\hline 1. Dark Triad & 3.36 & 1.06 & 0.84 & & & & & & & & & \\
\hline 2. Machiavellianism & 3.4 & 1.48 & 0.82 & $0.86^{* \star}$ & & & & & & & & \\
\hline 3. Narcissism & 3.93 & 1.35 & 0.77 & $0.68^{* *}$ & $0.39^{* *}$ & & & & & & & \\
\hline 4. Psychopathy & 2.74 & 1.32 & 0.77 & $0.75^{\star \star}$ & $0.56^{\star \star}$ & $0.21^{\star *}$ & & & & & & \\
\hline 5. Global Sociosexual Orientation & 13.55 & 5.3 & 0.87 & $0.39^{* *}$ & $0.35^{* *}$ & $0.27^{* \star}$ & $0.26^{\star *}$ & & & & & \\
\hline 6. Sexual Behavior & 9.41 & 5.59 & 0.79 & $0.25^{\star *}$ & $0.26^{* *}$ & $0.15^{*}$ & $0.15^{*}$ & $0.71^{* *}$ & & & & \\
\hline 7. Sexual Attitude & 17.84 & 7.39 & 0.86 & $0.31^{* *}$ & $0.27^{\star \star}$ & $0.21^{\star \star}$ & $0.22^{\star *}$ & $0.87^{\star *}$ & $0.54^{\star \star}$ & & & \\
\hline 8. Sexual Desire & 13.38 & 6.78 & 0.87 & $0.35^{\star \star}$ & $0.31^{* *}$ & $0.27^{\star *}$ & $0.26^{* *}$ & $0.79^{* *}$ & $0.30^{\star *}$ & $0.53^{\star *}$ & & \\
\hline 9. Religious affiliation & 0.41 & 0.49 & N/A & ns & ns & ns & $-0.18^{*}$ & $-0.18^{* *}$ & $-0.15^{*}$ & $-0.24^{* *}$ & ns & - \\
\hline
\end{tabular}

Table 1: Correlation coefficients between the Dark Triad composite and traits (Machiavellianism, narcissism, and psychopathy), global sexual orientation and it's dimensions (behavior, attitude, and desire), and religious affiliation. Note: $\alpha=$ Cronbach's $\alpha ; M=m e a n ; S D=$ standard deviation; $\mathrm{ns}=$ non-significant; $\mathrm{N} / \mathrm{A}=$ not available; ${ }^{*} \mathrm{p}<0.01$, two-way, ${ }^{* *} \mathrm{p}<0.001$, two-way.

Step 1 in the three-step hierarchical regression analysis indicated that Dark Triad composite $(\mathrm{B}=1.928, \mathrm{SE} B=0.264, \beta=0.385, \mathrm{p}<$ $0.001)$ made a significant contribution to the regression model ( $\mathrm{F}(1$,
$307)=53.500, \mathrm{p}<0.001$ ), explaining $14.8 \%$ of the variation in global sociosexual orientation. In Step 2, the predictor variable Dark Triad (B $=1.863, \mathrm{SE} \mathrm{B}=0.261, \beta=0.372, \mathrm{p}<0.001)$ and the moderator variable 
religious affiliation $(\mathrm{B}=-1.633, \mathrm{SE} \mathrm{B}=0.562, \beta=-0.152, \mathrm{p}=0.004)$ produced a significant effect $(\Delta \mathrm{F}(1,306)=8.447, \mathrm{p}=0.004)$, explaining a further $2.3 \%$ of the variation in global sociosexual orientation. In step 3, the Dark Triad composite $(B=1.978$, SE $B=$ $0.348, \beta=0.395, p<0.001)$, religious affiliation $(B=-0.747$, SE $B=$ $1.846, \beta=-0.069, \mathrm{p}=0.686)$, and the interaction variable Dark Triad $\mathrm{x}$ religious affiliation $(\mathrm{B}=-0.266, \mathrm{SE} \mathrm{B}=0.528, \beta=-0.088, \mathrm{p}=0.614)$ explained $0.1 \%$ of the variation in global sociosexual orientation. Nevertheless, R2 was not significant $(\Delta \mathrm{F}=(1,305)=0.254, \mathrm{p}=0.614)$. The Dark Triad composite was the most significant predictor of global sociosexual orientation with all three variables explaining $17.2 \%$ of the variation in global sociosexual orientation. In other words, religious affiliation was not a significant moderator of the relationship between Dark Triad and global sociosexual orientation (Table 2).

\begin{tabular}{|l|l|l|l|l|l|l|l|l|l|}
\hline \multicolumn{3}{|l}{ Model 1 } & \multicolumn{3}{l|}{ Model 2 } & \multicolumn{3}{l|}{ Model 3 } \\
\hline & B & SE B & $\beta$ & B & SE B & $\beta$ & B & SE B & $\beta$ \\
\hline Dark Triad & 1.93 & 0.26 & $0.39^{\star *}$ & 1.86 & 0.26 & $0.37^{\star *}$ & 1.98 & 0.35 & $0.40^{\star *}$ \\
\hline Religious affiliation & & & & -1.63 & 0.56 & $-0.15^{\star}$ & -0.75 & 1.85 & -0.07 \\
\hline $\begin{array}{l}\text { Dark Triad x Religious } \\
\text { affiliation }\end{array}$ & & & & & & & -0.27 & 0.53 & -0.09 \\
\hline R2 & & 0.15 & & & 0.17 & & & 0.17 & 0.25 \\
\hline$\Delta \mathrm{F}$ & & $53.50^{\star *}$ & & & $8.45^{*}$ & & & & \\
\hline
\end{tabular}

Table 2: Moderation Multiple Regression Analyses for the Dark Triad composite as the predictor of global sociosexual orientation and religious affiliation as the moderator.

Note: ${ }^{*} \mathrm{p}<0.01$, two-way, ${ }^{* *} \mathrm{p}<0.001$, two-way.

\section{Limitations and Concluding Remarks}

The unequal gender distribution with male preponderance may have influenced the result since males show greater propensities for scoring higher on Dark Triad character traits $[1,10]$, whereas women tend to be less permissive of casual sex [27] and to also report more religious engagement [25] compared to men. In addition, some of the associations found here might arise from hormonal differences between males and females or differences in social obligations/pressure as well.

Another advantage would have been to ask participants to separately identify as atheist, agnostic or "believe in God but not affiliated with a formal religion". After all the general category of "not affiliated" is not easily understood, that is, there could be many individuals who do believe in a higher power but simply don't identify with formal affiliations. Also in this line, the validity of the measure used here to operationalize the dark traits, the Dark Triad Dirty Dozen, has been critizised [28-31]. Future studies should test measures included in different studies [32], such as, Jones and Paulhus the Short Dark Triad and also single measures of each malevolent trait [33], such as, the Mach-IV and the Narcissistic Personality Inventory. Additionally, for the Dark Triad Dirty Dozen we opted to use a 7-point Likert scale [21], but other studies have used a 5-point Likert scale $[11,20]$ or even a 9-point Likert scale [10]. Hence, it is difficult to compare samples and our findings need to be replicated using more reliable measures of the Dark Triad. However, an advantage in the present study was that of a relatively high age mean ( 31.96 years of age) and a relatively wide age range (between 18 and 71 years of age). Also, at least half the participants lived in partnership relations and had jobs whereas job-seekers and students accounted for just $10 \%$ each. These characteristics of the sample are important in the context of sociosexual behavior and attitudes. Although religious affiliation did not moderate the Dark Triad relationship to global sexual orientation, our findings confirm the impact of religiousness/spirituality upon aspects of malevolent character, that is, deviant sexual orientation.

"Evelyn, I'm sorry. I just, uh... you're not terribly important to me." From the movie American Psycho.

\section{References}

1. Paulhus DL, Williams KM (2002) The Dark Triad of personality: Narcissism, Machiavellianism and psychopathy. J Res Personal 36: 556-563.

2. Furnham A, Richards SC, Paulhus DL (2013) The Dark Triad of Personality: A 10 Year Review. Soc Personal Psychol Compass 7: 199-216.

3. Christie RC, Geis FL (1970) Studies in Machiavellianism. New York: Academic press.

4. Judge TA, Piccolo RF, Kosalka T (2009) The bright and dark sides of leader traits: A review and theoretical extension of the leader trait paradigm. Leadership Quart 20: 855-875.

5. McHoskey JW (2001) Machiavellianism and sexuality: On the moderating role of biological sex. Pers Indiv Differ 31: 779-789.

6. McHoskey JW (1999) Machiavellianism, intrinsic versus extrinsic goals, and social interest: A self-determination theory analysis. Motiv Emotion 23: $267-283$.

7. Farwell L, Wohlwend-Lloyd R (1998) Narcissistic processes: Optimistic expectations, favorable self-evaluations, and self-enhancing attributions. J Pers 66: 65-83.

8. Blair CA, Hoffman BJ, Helland KR (2008) Narcissism in organizations: A multisource appraisal reflects different perspectives. Hum Perform 21: 254-276.

9. Williams KM, Nathanson C, Paulhus DL (2003) Structure and Validity of the Self- Report Psychopathy Scale-III in Normal Populations. Poster presented at the 111th meeting of the American Psychological Association, Toronto.

10. Jonason PK, Webster GD (2010) The Dirty Dozen: A concise measure of the Dark Triad. Psychol Assessment 22: 420-432.

11. Jonason PK, Slomski S, Partyka J (2012) The Dark Triad at work: How toxic employees get their way. Pers Indiv Differ 52: 449-453. 
Citation: Haddad B, Angman M, Archer T, Garcia D (2016) Dark Triad, Sociosexual Orientation and Religious Affiliation: An Association and Moderation Study. Clin Exp Psychol 2: 124. doi:10.4172/2471-2701.1000124

Page 5 of 5

12. Jonason PK, Valentine KA, Li NP, Harbeson CL (2011) Mate-selection and the Dark Triad: Facilitating a short-term mating strategy and creating a volatile environment. Pers Indiv Differ 51: 759-763.

13. Webster GD, Bryan A (2007) Sociosexual attitudes and behaviors: Why two factors are better than one. J Res Pers 41: 917-922.

14. Simpson JA, Gangestad SW (1991) Individual differences in sociosexuality: evidence for convergent and discriminant validity. J Pers Soc Psychol 60: 870-883.

15. Penke L, Asendorf JB (2008) Beyond global sociosexual orientations: a more differentiated look at sociosexuality and its effects on courtship and romantic relationships. J Pers Soc Psychol 95: 1113-1135.

16. Kämmerle $M$, Unterrainer HF, Dahmen-Wassenberg $P$, Fink A, Kapfhammer HP (2014) Dimensions of Religious/Spiritual Well-Being and the Dark Triad of Personality. Psychopathology 47: 297-302.

17. Koenig HG, McCullough ME, Larson DB (2001) Handbook of Religion and Health. New York: Oxford University Press.

18. Garcia D, Adrianson L, Archer T, Rosenberg P (2015) The Dark Side of The Affective Profiles: Differences and Similarities in Psychopathy, Machiavellianism, and Narcissism. Sage Open 5: 4.

19. Buhrmester M, Kwang T, Gosling SD (2011) Amazon's Mechanical Turk: A new Source of Inexpensive, Yet High-Quality, Data?. Perspect Psychol Sci 6: 3-5.

20. Jonason PK, Li NP, Czarna AZ (2013) Quick and Dirty: Some psychosocial costs associated with the Dark Triad in three countries. Evol Psychol 11: 172-185.

21. Jonason PK, Luévano VX (2013) Walking the thin line between efficiency and accuracy: Validity and structural properties of the Dirty Dozen. Pers Indiv Differ 55: 76-81.

22. Kleinbaum DG, Kupper LL, Nizam A, Rosenberg ES (2014) Applied Regression Analysis and Other Multivariable Methods.
23. Foster JD, Shrira L, Campbell WK (2006) Theoretical models of narcissism, sexuality, and relationship commitment. J Soc Pers Relat 23: 367-386

24. Jonason PK, Li NP, Webster GW, Schmitt DP (2009) The Dark Triad: Facilitating short-term mating in men. Eur J Personality 23: 5-18.

25. Rowatt WC, Schmitt DP (2003) Associations Between Religious Orientation. J Sci Stud Relig 43: 3.

26. Schmitt DP, Shackelford TK, Duntley J, Tooke W, Buss DM (2001) The desire for sexual variety as a key to understanding basic human mating strategies. Pers Relationship 8: 425-455.

27. Oliver MB, Hyde JS (1993) Gender differences in sexuality: A metaanalysis. Psychol Bull 114: 29-51.

28. Kajonius PJ, Persson BN, Rosenberg P, Garcia D (2016) The (mis)measurement of the Dark Triad Dirty Dozen: Exploitation at the core of the scale. Peer J 4: e1748.

29. Lee K, Ashton MC, Wiltshire J, Bourdage JS, Visser BA, Gallucci A (2013) Sex, power, and money: Prediction from the Dark Triad and HonestyHumility. Eur J Personality 27: 169-184.

30. Miller JD, Lynam DR (2012) An examination of the Psychopathic Personality Inventory's nomological network: A meta-analytic review. Personal Disord 3: 305-326.

31. Paulhus DL, Jones DN (2014) Measuring dark personalities.

32. Garcia D, Rosenberg P (2016) The Dark Cube: Dark and Light Character Profiles. Peer J 4: e1675.

33. Garcia D, Sikström S (2014) The dark side of Facebook: Semantic representations of status updates predict the Dark Triad of personality. Pers Indiv Differ 67: 92-94. 